\title{
The impact of neoliberal policies during the Great Recession on youth transition regimes in Spain and the United Kingdom
}

\author{
Martí López-Andreu, University of Manchester, UK. \\ Joan Miquel Verd, Universitat Autonoma de Barcelona, Spain.
}

\begin{abstract}
This article analyses the impact of the 2008 recession and subsequent austerity policies on the youth transition regimes of Spain and the UK. These two countries have different employment and social support models. However, both applied similar economic and policy responses to the 2008 recession, which had a marked neoliberal character. The article identifies whether or not the impact of these policies blurred the defining characteristics of their transition regimes. To do so, an analysis of employment and welfare policies is undertaken, and two key dimensions of youth transition regimes are critically analysed: the characteristics of employment and the forms of independent living. Our findings show that market dependence and the importance of class-related factors have been reinforced. Nevertheless, these similar patterns of change go together with the persistence of differences among regimes, which suggests that the effect of neoliberal policies is far from being uniform and systematic.
\end{abstract}

\section{Keywords}

Youth transition regimes, austerity, neoliberalism, employment, recession, Spain, United Kingdom

\section{Introduction}

This article addresses the impact of the 2008 recession and subsequent policy responses on the youth transition regimes of Spain and the UK. The term youth transition regime refers to the institutional configuration and social policies belonging to a certain welfare model when young populations are considered (Walther, 2006, 2017).

Although Spain and the UK have different employment and social protection models, both of them applied similar economic and policy responses to the 2008 recession. These policy responses have a strong neoliberal character, understood as reinforcing the role of the market as provider of resources and services (Taylor-Gooby, 2012; Peck and Theodore, 2019), which had the effects of reducing the supports available to young adults and reinforcing inequalities (Means, 2017). However, it is important to bear in mind that public policies are embedded in broader institutional arrangements that affect youth transitions, and hence country-specific institutional differences and domestic driving forces have an influence on the policies applied (Tosun et al, 2019). That said, the diversification and disarray of youth transitions (Furlong and Cartmel, 2007) is a long-term trend that highlights the importance of considering not only policies but also the institutional configurations and options of young individuals in their paths to adulthood, i. e. those different realities in which young people's biographies are embedded. In this sense, the term youth transition regime is useful to grasp the way youth and youth transitions are institutionally constructed, as there is a correspondence between welfare regimes and youth transition regimes (Walther, 2017). ${ }^{1}$

Yet, an institutionalist approach based on the analysis of welfare regimes, or more concretely of youth transition regimes, does not deal easily with the transformational and restructuring character of capitalist development (Harvey, 2005). As stated by Pierson (2004), classical 
institutionalist analysis developed a theory of change that emphasizes the role of history, continuity and tradition generating path-dependency effects. Conversely, the work of Streeck and Thelen (2005) identified how gradual change can lead to institutional transformation. Following this approach that acknowledges institutional change, scholars from critical political economy have developed useful concepts to analyse the effect of neoliberal policies in employment and labour market institutions. Baccaro and Howell (2017) have identified two movements towards neoliberalism: institutional change and institutional outcomes. The first relates to changes in institutional barriers and policies aiming to reinforce employers' discretion in the labour market. It also includes cutbacks and even the withdrawal of specific social policies and, more importantly, a change in existing policies towards the reinforcement of individual responsibility. The second focuses its attention on processes happening through mostly unchanged institutions and highlights the importance of the outcomes of models and regimes. Crucially, this line of inquiry emphasizes the need to go beyond the institutional formal characteristics and pay attention to the outcomes of specific employment and social models.

Following the above-mentioned line of inquiry, the approach we develop in the article tries to overcome the classical institutionalist approach by highlighting the profound effects of neoliberal policies on the employment regulation and social policies affecting youth transitions. Given that the characteristics of these policies have been very similar in Spain and the UK, the question we pose is whether they produced similar outcomes in two key dimensions of youth transitions: the characteristics of employment and the forms of independent living. Moreover, as far as each country is representative of a different youth transition regime, we ask whether these neoliberal policies led to the blurring (or not) of the differences between regimes. In other words, this latter question puts forward whether the modification of the institutional arrangements caused by neoliberal policies results in a convergence to a unique institutional model, namely the liberal one, or, on the contrary, the trend towards marketization 'simply' destabilizes the transition regimes considered.

To empirically answer the questions posed, the changes in three critical areas of regulation affecting youth transitions -labour market rules, in-work and out-of-work benefits, and child and household benefits- are identified and discussed against the institutional characteristics of each regime. Second, the European Union Statistics on Income and Living Conditions (EUSILC) provided by Eurostat are used to identify the impact at a societal level of the recession and the institutional changes identified. Two years are analysed, 2007, defined as the prerecession period, and 2013, which has been chosen to grasp the effect of the 2008 recession and the implementation of austerity policies since 2010 in both countries. Our findings suggest that although there has not been a clear trend towards a convergence of youth transition regimes toward a common 'neoliberal model', a shift in the characteristics of youth employment and the forms of independent living has occurred. These changes reveal the harsher conditions in which youth transitions develop and a stronger role of socio-economic inequalities. Certainly, the analysis is limited to the period considered, and the changes are ongoing, however, at present, the effects of the crisis persist among the youth population in both countries (Hvinden et al, 2019). 
This article provides an alternative point of view to understand the effects of market-based institutional and policy responses on different youth transition regimes and contributes to the existing academic literature on comparative approaches to youth transitions (e.g. Parreira do Amaral et al, 2013; Tikkanen et al, 2017; Irwin and Nilsen, 2018) by offering an approach that integrates into the discussion the transformative and dynamic character of capitalist development underlined by critical political economy scholars (Baccaro and Howell, 2017). To our knowledge, a comparative analysis of the effects of neoliberal policies on the institutional configuration of transition regimes has not yet been addressed. This comparative approach addresses the question of how neoliberal policies produce both similar and different institutional responses and effects, and it highlights how these policies affect the employment and welfare models as pillars of youth transition regimes. In our case, we consider two countries belonging to two different specific regimes and we focus on two particular dimensions of youth transitions: the characteristics of employment and the forms of independent living.

The article is organized as follows. First, the theoretical framework is presented with two differentiated sub-sections. The next section describes the methods used in our analysis. This is followed by the findings, which are also organized in two sub-sections. Finally, the last section discusses the results and highlights how and to what extent the young population and youth transition regimes have been affected by the recession and the subsequent changes in employment regulations and social policies.

\section{Theoretical framework: Neoliberalism, institutional change and the 2008 recession effects on youth}

\section{Neoliberal policies and their effects on institutional arrangements}

The work of Harvey (2005) suggests that the world has experienced a turn towards neoliberalism in political-economic practices and thinking since the 1970s. More concretely, the author defines neoliberalism as a political project focused on the restoration of class power threatened by the redistribution of wealth and income following World War II. From this point of view, neoliberalism would be developed against the specific balance of power between actors in a given society and affecting those institutions of welfare and employment regulation that contributed to the decommodification of people's lives in specific institutional configurations (Peck and Theodore, 2019). The institutional arrangements that characterize youth transition regimes have not escaped this trend, especially after the 2008 recession. After the period of fiscal stimuli that characterized policy responses during the first stage of the recession, a second phase characterized by fiscal austerity was developed (Heyes et al, 2012). In this austerity phase, both in Spain and the UK, recommodification policies were implemented (Grimshaw, 2015; Banyuls and Recio, 2015). The coalition government (between Conservatives and Liberal Democrats) in office in 2010 in the UK implemented a harsh program with budgetary restrictions, especially affecting the public sector, and leading to the withdrawal and cutbacks of several social policies. In Spain, the U-turn in the management of the crisis by the Socialist Party in power in 2010 resulted in a drastic reform of the labour market and substantial budgetary cuts. Furthermore, the conservative government that replaced the Socialist Party in office in November 2011 reinforced these trends. In both countries, the cutbacks on several welfare and social policies, together with the measures affecting employment regulation and collective bargaining, jeopardized the sources of resources and supports for young people (Muñoz de Bustillo and Antón, 2011; Rubery and Grimshaw, 2012). 
However, the analysis of these neoliberal policies should go beyond the examination of their effects on the institutional arrangements affecting young people to look at the uneven effects that the outcomes of these policies have on youth transitions, as stated in our introduction. Scholars such as Hermann (2014) and Carroll et al (2019) have highlighted that institutionalist analysis have tended to misjudge the power of exogenous shocks and supranational institutions in enforcing neoliberal institutional convergence and have ignored the role of ideology and class interests in imposing a particular solution on an economic problem. Similarly, Means (2017) has emphasized that traditional approaches that analyse youth unemployment, such as the Human Capital and the Keynesian approach, fail to acknowledge the power and class dynamics that define capitalism. These authors have advocated for the need to recognize the inherently contradictory, conflictual, anarchic and fundamentally unruly nature of economic development. Furthermore, Brenner et al (2010) have argued that sometimes incrementally and sometimes through more dramatic ruptures neoliberalization processes have reshaped the contours of inherited institutional landscapes. Crucially, these authors suggest that the facilitation of marketization and commodification have simultaneously intensified the uneven development of regulatory forms across places, territories and scales and, therefore, we cannot expect convergence towards one unique institutional model.

Another school of inquiry, related to the welfare state change, has centred the debate on how social models adapt and modernize to meet new needs (Taylor-Gooby, 2004). These authors highlight the potential for institutional innovation and point out the existence of processes in which existing resources may be combined in innovative and new ways that could transcend all models. In this regard, Rubery (2011) has identified a pattern of neoliberal change in social models in which neoliberal policies have been accompanied by the development of new areas of social intervention related to the emergence of new social needs. The latter include those areas of policy intervention generated by deregulation and expansion of market mechanisms but also include policies developed to cope with the needs resulting from patterns of secular change in the sphere of social reproduction (such as the greater presence of women in paid employment and changes in family and household composition). Significantly, the author argues that this has led to more 'hybrid' models and the expansion of the neoliberal rationale in social policies to cope with the new needs. From this point of view, models may have developed measures traditionally associated with other institutional settings to cope with changing social needs, and the development of these policies could have followed a neoliberal pattern and reinforced market mechanisms.

\section{Youth transition regimes of Spain and the UK}

As stated in the introduction, the term youth transition regime has been used as a way to focus and extend the work on welfare regimes (see Esping-Andersen, 1999; or Amable, 2003) to the analysis of youth and youth transitions (Walther, 2017). In this sense, youth transition regimes are an analytical construct that allow different countries sharing some common societal characteristics to be grouped in a few models. The main societal dimensions considered when building up the models of youth transition regimes vary depending on the specific authors using them and the specific issue considered (see Walther, 2006, 2017; Parreira do Amaral et al, 2013; Tikkanen et al, 2017). However, usual dimensions considered include: the sources of social support (state or family), the way education or training is institutionally organized, the structuring of youth labour markets and labour market entry, and/or the focus of transition policies (Walther, 2006; Parreira do Amaral et al, 2013; Tikkanen et al, 2017). 
In this article we will concentrate our analysis in two key dimensions of youth transitions: the characteristics of youth employment and the forms of independent living. In the following paragraphs these two dimensions will be characterized for Spain and the UK, highlighting the core features that place each country in different types of transition regimes, and the kind of supports that youth typically receive in each country.

The UK and Spain have been traditionally classified in different youth transition regimes. The UK has been classified as a liberal regime and Spain has been classified as sub-protective or under-institutionalized (Tikkanen et al, 2017; Walther, 2017). In general terms, the liberal regime characteristic of the UK is organized around the idea of economic independence. Social policies are geared towards preparing young people to take responsibility for their own lives, which implies supporting independent living at an early stage in their life trajectories and pushing them to obtain a job, disregarding the quality of employment (Walther, 2017). On the contrary, in the sub-protective regime that characterizes Spain, young people are not assigned a specific status, and, therefore, social policies do not focus specifically on them (Walther, 2006). This lack of public social support causes an important and long dependency on the family, which means that young people spend many years living with their parents and that transitions toward independent living occur relatively late in the trajectory (Walther, 2017).

Regarding the characteristics of youth employment, the British employment model is characterized by a high capacity to absorb new entrants due to the flexibility in recruitment practices and the lack of strong internal labour market ties (Rubery, 2010). The neoliberal approach also dominates in employment regulation (Kretsos and Martinez Lucio, 2013). However, during the New Labour government (1997-2010) a double approach combined neoliberalism with the development of specific policies, mainly designed to support families with low incomes and to address growing child poverty, including means-tested measures such as child and household benefits and working tax credits (Rubery, 2010). In contrast, the Spanish employment model was once characterized by its relatively high employment protection for those with permanent contracts. However, several authors have highlighted that long before the recession the Spanish model moved slowly toward a 'Mediterranean neoliberalism' (Banyuls et al, 2009) and has been affected by the contradictory tendencies of equality demands and neoliberal reforms since the transition to democracy (Miguélez and Recio, 2010). Hence, the youth population in the Spanish labour market is characterized by high temporary employment rates and high unemployment in recession periods (Verick, 2011).

Regarding the role of families, in the liberal regime where the UK is placed, traditional family strategies have been based more in supporting independent living and studies outside of the home, and less in material well-being (Hodsworth, 2004). In spite of this, the family played a significant role in different life stages and transitions in pre-recession UK. The introduction of high education fees since the 2000 s resulted in a growth in the number of higher education students living in their parents' home and an increase in the number of young people sharing accommodations (Stone et al, 2011). In the sub-protective regime, where Spain is placed, care and financial support across generations are traditionally provided by family. As a result, a culture of parental dependency exists as a strategy for accumulating economic resources and for coping with risks (Moreno, 2012). 


\section{Methods}

The analysis of the effect of 2008 recession and austerity policies in the UK and Spain is developed in two parts. First, the main changes in employment regulation and social policies in both countries are discussed in relation to the institutional characteristics of each regime. Second, the European Union Statistics on Income and Living Conditions (EU-SILC) provided by Eurostat are used to discuss the impact of the crisis and neoliberal policies on two key dimensions of youth regimes: the labour market situation and independent living of young adults. In this second part we pay attention to the aggregated outcomes produced by the changes in the regulations considered in the first section. In this way, we follow the Baccaro and Howell (2017) analytical proposal as we focus on the policies' effects on the labour market status and independent living of young people. This database is especially useful for our purposes as it allows us to undertake analyses based in the household, its characteristics and the characteristics of its members. Furthermore, EU-SILC is the only harmonized database at EU level that permit a comparative analysis on this issue.

In this second part, the EU-SILC raw data has been used to undertake a descriptive analysis to obtain an overview of the effects of policies at a societal level, identifying differences among different social profiles. ${ }^{2}$ Two key dimensions of youth transitions have been addressed: the characteristics of employment and the forms of independent living. To do so, firstly, the distribution of young adults in relation to labour market status has been considered by analysing the following situations: employment, unemployment, education and training, domestic tasks and other inactivity situations. Secondly, three possibilities of flexible employment have been included: part-time employment, involuntary part-time employment and temporary employment. Third, the authors have clustered young adults according to their independent living situation: individual, couple and sharing. Furthermore, the tenure status (renting/owning) for each resulting cluster has been considered. Finally, educational level has been included as a way to address the socio-economic conditions that underlie the differences in the observed outcomes. Two years are analysed: 2007, defined as the pre-recession period, and 2013, which has been chosen to grasp the effect of the 2008 recession and the implementation of austerity policies since 2010 in both countries. Young adults have been identified as individuals aged between 20 and 29 years old. Using an age bracket up to 29 years old allows for a good comparison between independent living transitions of British and Spanish young people, as these transitions occur in Spain at a later age than in the UK.

\section{Findings}

\section{Neoliberal trends in employment regulation and social policies}

This section describes the reforms and changes in three areas that are crucial providers of resources and support for young adults: employment regulation, in-work and out-of-work benefits and child and household benefits. Three main patterns have been identified that erode the supports coming from the employment regulation and welfare policies. First, a clear trend towards more flexible employment and collective bargaining regulation has been identified in both countries. Second, benefits have been reduced and their conditionality has been reinforced. Finally, broader social policies, such as household and child benefits, suffered significant cutbacks that further jeopardized institutional supports. 
The neoliberal approach towards employment rights strengthened in the UK after the onset of the crisis. The period before unfair dismissal can be claimed was extended from 12 to 24 months and the minimum consultation period for collective redundancies was reduced from 90 to 45 days for large-scale redundancies. Furthermore, the 'two-tier code', a measure that ensured that public sector agreements were in practice and which was extended to workers in private sector organizations subcontracting services to the public sector, was abolished (Rubery and Grimshaw, 2012).

The unemployment benefits also suffered important changes. The job seeker allowance (JSA), already limited and affected by high controls, suffered substantial cuts, including, since 2011, a change in the calculation of its increase in line with the Consumer Price Index instead of the Retail Price Index (which tends to be higher). These cuts affected other benefits such as housing benefits and working tax credits. At the same time, a delay on receiving the allowance was introduced in 2013, as the so-called 'new upfront work search' imposed a 7-day period for jobseekers before getting the allowance (Grimshaw, 2015). Furthermore, the funding of the job centres suffered significant cutbacks and some of their activities were outsourced to 'prime contractors'. Accordingly, a system was established in which, after the first 12 months, private sector contractors took charge of payments, and control of benefits and were rewarded according to the number of unemployed who found jobs. Moreover, compulsory 'voluntary' work of up to 30 hours per week was introduced as a possibility for those receiving the allowance.

Regarding the household and low-income family benefits, working tax credits (WTC) and educational maintenance allowance (EMA) were the most affected by changes. Reforms to WTC included a less favourable uprating index, the need for couples to work more hours to access benefit (a change from 16 to 24 hours per week in total) and a reduction of the amount related to child care (Grimshaw, 2015). Furthermore, additional restrictions were introduced to prevent an individual to be inactive and keep benefits if another adult in the household was unemployed. The change for EMA was more significant in that it was simply eliminated. This measure provided income to 16-19 year-olds from low income families to remain in education. Furthermore, university fees tripled in the same period, making it more difficult to attend higher education (Rubery and Grimshaw, 2012). On the other hand, household benefits, managed by local authorities, suffered significant cutbacks, including the increase of benefits in line with inflation and not with the local market price of renting (Grimshaw, 2012). Moreover, the socalled 'bedroom tax' (resulting in a decrease of benefits) was introduced for those in social housing with one or more rooms not occupied.

In Spain, employment regulation was deeply affected by three labour market reforms in 2010, 2011 and 2012 (López-Andreu, 2019a). The reasons for fair dismissal (with lower redundancy costs) were expanded, including current or future economic losses. Furthermore, the unfair dismissal payment was reduced from 45 to 33 days per year worked, and a new permanent contract was launched for companies of less than 50 workers with a year probationary period and different subsidies for the employer. Moreover, administrative procedures in collective redundancies were shortened, reducing the 'bargaining time' traditionally used by unions to improve redundancy conditions. Another area of employment regulation that was affected by drastic changes was collective bargaining. The changes implied a clear movement towards 'disorganized decentralisation,' (Marginson et al, 2014) in which the priority of company-level agreements over multi-employer agreements on working conditions were established, and the capacities of the employer to unilaterally modify salaries and working time were strengthened by including future losses as a justified cause (Banyuls and Recio, 2015). 
The unemployment benefit system in Spain had few changes with the onset of recession. The contributory nature of unemployment benefit means that the main inequalities relate to the previous employment situation, so people without long periods of continuous employment contribution have difficulties to access the system. Thus, young workers in temporary jobs or with discontinuous labour market participation had difficulties reaching the minimum period of 360 days of work to access the benefit. The importance of unemployment benefit in Spain is based in being, in many cases, the only policy that implies substantial income transference, as other policies such as means-tested benefits, child and household benefits are underdeveloped. Nevertheless, some significant changes were applied during the austerity period. First, in 2011, the unemployed were required to accept any training offered by the Public Employment Service, and second, in 2012, contributory benefit was reduced by cutting the benefit from $60 \%$ of median contribution of the last six months at work to $50 \%$ after six months of unemployment.

Family and household support policies in Spain were also affected by public budget cuts. With an impact on young adults' lives, the Emancipation Basic Income, an income tested housing benefit for renting houses for people between 22 and 29 years old and established in 2009, was abolished at the end of 2011. The so-called 'baby cheque', a one-off cash benefit of 2,500 euros for the birth or adoption of a child, was eliminated at the end of 2010 (Salido, 2011). Additionally, university fees increased and multiplied by two or three times in some cases, and the conditions for accessing education grants were hardened (Muñoz de Bustillo and Antón, 2013).

\section{The erosion of employment and independent living options for young adults}

In this section we identify how the changes at the institutional level have modified the outcomes or situations of young adults in relation to employment and independent living status. Both aspects are an indicator of the life course development and transitions of young adults before and after the 2008 recession.

Table 1 shows that both in the UK and Spain the labour market insecurities of young people increased. However, there are important differences related to the characteristics of the different employment models. From 2007 to 2013 there was a decrease in the employment of young adults in the UK by almost 6 points, related to an increase by 2.4 points in education and training and by 3.2 in unemployment. In the Spanish case, the changes were deeper. Starting from a worse situation, employment fell by more than 22 points, unemployment grew by 18 points and there was an increase in education and training by more than 6 points.

\section{[Table 1 about here]}

Table 2 shows the effect of the crisis on non-standard employment. From 2007 to 2013, in parallel with the growth of unemployment, there was an increase of non-standard employment in both countries. In the UK, part-time employment increased across all educational levels, but the growth was especially high in middle educational levels. In Spain the proportion of young part-time workers skyrocketed from $11.4 \%$ to $25.1 \%$ and overtook the UK $(21.7 \%)$, revealing a significant change in the pattern of employment for young adults in Spain and some convergence towards low working hours. This increase in part-time employment for Spanish young adults especially affected middle and high educational levels. The increase of part-time jobs in Spain correlated with a dramatic growth of involuntary part-time employment by almost 
31 points, reaching $48.4 \%$ and affecting all educational groups. These findings corroborate previous analyses that have identified the spread of job insecurity to higher educational levels during the crisis (López-Andreu and Verd, 2016). Involuntary part-time employment also grew in the UK by more than 9 points and reached $23.9 \%$. Temporary employment remained stable in the UK and increased by 2.3 points in Spain. Therefore, Spanish young adults faced more insecure jobs both in terms of working hours and in terms of the duration of the contract. While the latter has been a traditional feature of Spanish youth employment, the former reveals an added insecurity dimension. The insecurity in terms of working hours is also shared by British young adults.

\section{[Table 2 about here]}

Table 3 shows the changes in the percentage of adults leaving their parents' house in both countries. The data before the crisis (2007) confirms that Spanish young adults tended to achieve independent living much later than their British counterparts. The 58.8\% of the young adults aged 20-29 in the UK had left their parents' house in contrast with just the $32.5 \%$ in Spain. Furthermore, the data also reveals different patterns according to educational level. While just the $32 \%$ of Spanish young adults with higher educational levels left their parent's home, in the British case the rate was above $74 \%$.

\section{[Table 3 about here]}

Considering the impact of the recession and austerity, Table 3 shows that from 2007 to 2013 the rate of independent living slightly decreased in Spain by -0.7 percentage points. A more detailed analysis reveals that this was related to a deep fall of more than 10 points among young people with intermediate educational levels, while independent living increased in low and higher educational levels by 2 and 2.7 points respectively. This suggests that this group with a middle educational level tended to delay transition to independent living, and possibly, pursued education. Table 4.2 shows that this group suffered significant falls in independent living situations in owning status that was not compensated by the growth in renting, as happened in low and higher educational levels (Tables 4.1 and 4.3).

In the British case, the rate of independent living slightly increased by 0.3 points. However, this increase only affected low educational levels as middle and especially higher educational levels decreased by -1.7 and -7 points respectively. This data allows us to identify that some groups tended to achieve independent living irrespective of the employment situation or family support. In contrast, independent living dramatically fell among those with higher educational levels. The latter suggests that those groups with a higher social position were remaining at their parents' home as far as the conditions for independent living were harsher.

[Table 4.1 about here]

[Table 4.2 about here]

[Table 4.3 about here]

[Table 4.4 about here]

The data shown in Table 4.4. allows us to identify the changing patterns in the forms of independent living along the period we are analysing. The figures show that in both countries 
owning dominated before the crisis (2007), reaching about a similar $75 \%$ in both countries. Since the crisis, a dramatic change has occurred, and renting shows a significant growth in both countries. This is especially the case in the UK, in which renting increased in all types of independent living and replaced owning as the dominant pattern (in 2013, 75.5\% of young adults are renting). The latter highlights that the conditions of the labour market (unemployment and low working hours) and the erosion of institutional support decreased young adults' capacities to access mortgages. Furthermore, the data reveals a decrease in individual and couple arrangements and an increase by almost 10 points in sharing. Although some cultural changes can explain this trend, the fact that the higher increase in sharing (22.7 points) is found in low educational levels (Table 4.1.) suggests that the difficulties to achieve independent living as an individual and as a couple have led to the growth of sharing. This suggests again that while some groups could have postponed independent living and relied on family support (cohabitation), others had to pursue independent living regardless of their living conditions.

In Spain, the data in Table 4.4. shows an increase in renting up to 59.7\%. This lower increase in Spain in comparison with the UK relates to the lowest percentage of young adults living independently in Spain identified above. In this case, individual independent living increased by 14 percentage points, while living in a couple and sharing decreased. The data reveals that the increase of individual living and renting affected all educational levels, but it is higher in low educational levels, as revealed by Table 4.1. Conversely, the deep falls in sharing and couple owning in all educational levels suggest that these types of arrangements have been the most affected by the crisis and austerity policies.

Overall, these results show that the changes in independent living in the UK have been characterized by a growth in sharing and renting as a response to the difficulties to access mortgages. Furthermore, the data reveals a delay in independent living for middle and especially higher educational levels, suggesting that these groups are delaying independent living as a way to accumulate resources. In the Spanish case, couple and sharing arrangements have decreased, especially in middle educational levels. The latter suggests that the crisis and the decrease of institutional supports have tended to delay a specific pattern of independent living that characterizes the transitions in Spain (living in a couple and owning). However, the data also highlight the erosion of more contemporary patterns as there has been a significant decrease in sharing arrangements (mainly in those with middle and higher education).

\section{Discussion and conclusions}

This article has concentrated on discussing the impact of the 2008 recession and subsequent neoliberal policies on the youth transition regimes of Spain and the UK. To do so, the article has concentrated on two key dimensions of youth transitions: the characteristics of employment and the forms of independent living; and it has analysed them following the suggestion of critical political economy scholars to give greater attention to the dynamics of transformation and change and to the outcomes these changes produce. The comparison of Spain and the UK are of interest because both countries applied similar policy responses during the 2008 recession even though their institutional configurations are clearly different. This analysis has allowed the identification of, first, whether or not these policies similarly affected social profiles of the young population in Spain and the UK, and, second, whether or not they led to the blurring of the differences between the regimes. 
The findings reveal that during recession and austerity, the youth regime models of both countries maintained their characterizing features. In the UK, emancipation happened earlier than in Spain and there was a higher integration of young adults into employment. Conversely, Spanish young adults were more likely to pursue education and training and tended to delay independent living. Furthermore, the highest rate of independent living of British young adults was still related to a higher percentage of renting, sharing and individual independent living than in Spain. However, in both cases we found that marketization destabilized some of the characteristics of the models leading to more uneven and hybrid forms. We have identified that both countries were affected during the recession and austerity period by policies that reinforced neoliberal trends in the regulation of the labour market and in welfare and social policies. The UK was already one of the most flexible employment models in Europe, although reforms during recession reinforced its neoliberal characteristics. On the other hand, Spain suffered a deep change in their employment model, although deregulation of employment and collective bargaining had already begun before recession. Furthermore, employment-related benefits suffered significant cutbacks in both countries, especially in the UK, that withdrew some of the improvements developed in the previous period. This is also the case of Spain, where the newly introduced in-cash transferences for children were withdrawn. Accordingly, we found that neoliberal policies have not created distinct institutional environments for young people, and that a convergence in a unique model has not occurred. In this sense, we agree with Brenner et al (2010) in that path-dependency makes it possible to explain the differences between institutional models while, at the same time, acknowledging the cumulative impacts of different neoliberalization waves.

However, the review of the changes in employment and welfare policies reveal that while the models maintained their main characteristics, the trend has been towards the reinforcement of social inequalities in young adults' options, and, in both countries, labour market inequalities have been strengthened. This is in line with the authors that identify neoliberalism as a political project to restore class power (Harvey, 2005). Hence, the employment and social policies that allowed for a relative decommodification and permitted individuals (or young adults in the case of our analysis) to achieve their personal and social goals have been eroded in both countries, leading to more class related options in their life course (Irwin and Nilsen, 2018; Verd et al, 2019; Bolibar et al, 2019). In both countries, the employment situation of young adults has deteriorated, resulting in more unemployment and more unsecure work, in parallel to a decrease in policies to support the independent living of young adults. The findings reveal the crucial role that socio-economic origin and family support play in the options and possibilities for independent living. Some groups, mostly those with a low educational level and potentially less capacity to rely on family support, attained independent living irrespective of its conditions. Conversely, other groups delayed independent living, and, potentially relying on family support, pursued further education.

Thus, our findings reveal that although neoliberal policies during recession and austerity have not altered the basic features of the transitions defining the regimes considered, a common trend has been identified in terms of a reduction of institutional supports and the reinforcement of market and class related factors. Furthermore, the identification of similar paths of change, together with the persistence of differences among regimes, suggests that the effect of neoliberalism is far from being systematic and that we can characterize it as uneven (Brenner et al, 2010; Peck and Theodore, 2019) and leading to more hybrid and mixed forms between countries. Following Rubery (2011), our findings highlight that the destabilization of institutional regimes provoked by neoliberalism has led to the development of characteristics traditionally associated with other models. For example, this trend can be identified in the 
growing role of the family in youth transitions in the UK and in the trend towards reduction of employment protection and flexibilization of the Spanish labour market. However, it has also been noted that these trends began before the recession, showing that liberalization tendencies are far from being new and have been affecting welfare models for a long time (López-Andreu, $2019 b$ ). Therefore, this article remarks on the importance of gradual change (Streeck and Thelen, 2005) when discussing the impact of neoliberal policies.

\section{Acknowledgements}

We would like to thank to four anonymous referees for their comments, which enabled us to improve the quality of our paper. It goes without saying that any errors in this article are the sole responsibility of the authors.

\section{Notes}

${ }^{1}$ A broader and more precise definition of what constitutes a youth transition regime is presented in our theoretical framework. In this same section, the specific dimensions of the transition regimes that we will consider in the analysis are presented and discussed.

${ }^{2}$ A correlational approach was not considered, as far as the objective of the analysis was not identifying relationships between variables.

\section{References}

Amable B (2003) The Diversity of Modern Capitalism. Oxford: Oxford University Press.

Baccaro L and Howell Ch (2017) Trajectories of Neoliberal Transformation. European Industrial Relations Since the 1970s. Cambridge: Cambridge University Press.

Banyuls J, Miguelez F, Recio A et al (2009) The transformation of the employment system in Spain: towards a Mediterranean Neoliberalism. In: Bosch G, Lehndorff S and Rubery J (eds) European Employment Models in Flux. A Comparison of Institutional Change in Nine European Countries. New York: Palgrave, pp. 247-269.

Banyuls J and Recio A (2015) A crisis inside the crisis: Spain under a conservative neoliberalism. In: Lehndorff S (ed) Divisive integration. The triumph of failed ideas in Europe - revisited. Brussels: ETUI, pp. 39-68.

Bolíbar M, Verd JM and Barranco O (2019) The Downward Spiral of Youth Unemployment: An Approach Considering Social Networks and Family Background. Work, Employment and Society, 33(3): 401-421.

Brenner N, Peck J and Theodore N (2010) Variegated neoliberalization: geographies, modalities, pathways. Global Networks, 10(2): 182-222.

Carroll T, Gonzalez-Vicente R and Jarvis D (2019) Capital, conflict and convergence: a political understanding of neoliberalism and its relationship to capitalist transformation. Globalizations, 16(6): 778-803.

Esping-Andersen G (1999) Social Foundations of Postindustrial Economies. Oxford: Oxford University Press 
Furlong A and Cartmel F (2007) Young People and Social Change: New Perspectives. Maidenhead: Open University Press.

Grimshaw D (2012) Austerity, Privatisation and levelling down: Public sector reforms in the United Kingdom. In: Vaughan-Whitehead D (ed) Public Sector Adjustments in Europe, Geneva: ILO, pp. 575-626.

Grimshaw D (2015) Britain's social model: The rapid descent from liberal collectivism to a 'market society. In Vaughan-Whitehead D (ed) The European Social Model in Times of Economic Crisis and Austerity. Cheltenham and Geneva: Edward Elgar and ILO, pp. 419-462.

Harvey D (2005) A Brief History of Neoliberalism. Oxford: Oxford University Press.

Hermann C (2014) Structural Adjustment and Neoliberal Convergence in Labour Markets and Welfare: The Impact of the Crisis and Austerity Measures on European Economic and Social Models. Competition \& Change, 18(2): 111-130.

Heyes J, Lewis P and Clark I (2012) Varieties of capitalism, neoliberalism and the economic crisis of 2008-?. Industrial Relations Journal, 43 (3): 222-241.

Hvinden B, O'Reilly J, Schøyen M et al (eds) (2019) Negotiating early job insecurity: wellbeing, scarring and resilience of European youth. Edward Elgar: Cheltenham.

Irwin S and Nilsen A (eds) (2018) Transitions to adulthood through recession. Youth and inequality in a European comparative perspective. London: Routledge.

Kretsos L and Martinez Lucio M (2013) Destandardization of Employment in the UK: Issues, Politics and Policy Reinvention. In: Koch M and Fritz M. (eds) Non-Standard Employment in Europe. Paradigms, Prevalence and Policy Responses. Basingstoke: Palgrave Macmillan, pp. 103-116.

López-Andreu, M. (2019a) Employment Institutions under Liberalization Pressures: Analysing the Effects of Regulatory Change on Collective Bargaining in Spain. British Journal of Industrial Relations, 57 (2): 328-349.

López-Andreu M (2019b) Neoliberal trends in collective bargaining and employment regulation in Spain, Italy and the UK: From institutional forms to institutional outcomes. European Journal of Industrial Relations, 25(4), 309-325.

López-Andreu M and Verd JM (2016) Employment instability and economic crisis in Spain: what are the elements that make a difference in the trajectories of younger adults?. European Societies, 18 (4): 315-335.

Means A J (2017) Generational precarity, education, and the crisis of capitalism: Conventional, Neo-Keynesian, and Marxian perspectives. Critical Sociology, 43(3): 339-354

Marginson P, Keune M and Bohle D (2014) Negotiating the effects of uncertainty? The governance capacity of collective bargaining under pressure. Transfer, 20 (1): 37-51. 
Miguélez F and Recio A (2010) The uncertain path from the Mediterranean Welfare Model in Spain. In Anxo D, Bosch G and Rubery J (eds) The Welfare State and Life Transitions. Cheltenham: Edward Elgar Publishing, pp. 284-308.

Moreno A (2012) The Transition to Adulthood in Spain in a Comparative Perspective: The Incidence of Structural Factors. Young, 20 (1): 19-48.

Muñoz de Bustillo R and Antón J-I (2011) From the highest employment growth to the deepest fall: Economic crisis and labour inequalities in Spain. In: Vaughan-Whitehead D. (ed) Inequalities in the world of work: The effects of the crisis. Geneva: ILO, pp. 393-444.

Muñoz de Bustillo R and Antón J-I (2013) Those were the days, my friend: The public sector and the economic crisis in Spain. In Vaughan-Whitehead D. (ed) Public Sector Shock. The Impact of Policy Retrenchment in Europe. Geneva: ILO, pp. 511-542.

Parreira do Amaral M, Walther A and Litau J (2013) Governance of educational trajectories in Europe. Access, coping and relevance of education for young people in European knowledge societies in comparative perspective. Final Report of the GOETE project. Frankfurt a.M.

Peck T (2019) Still neoliberalism?. South Atlantic Quarterly, 118 (2): 245-265.

Pierson P (2004) Politics in Time. Princeton: Princeton University Press.

Rubery J (2010) The UK welfare state: more than residual but still insufficient. In: Anxo D, Bosch G and Rubery J (eds) The Welfare State and Life Transitions. Cheltenham: Edward Elgar Publishing, pp. 78-103.

Rubery J (2011) Reconstruction amid deconstruction: or why we need more of the social in European social models. Work, Employment and Society, 25 (4): 658-674.

Rubery J and Grimshaw D (2012) The end of the UK's liberal collectivist social model? The implications of the coalition government's policy during the austerity crisis. Cambridge Journal of Economics, 36 (1): 105-126,

Salido O (2011) Female Employment and Policies for Balancing Work and Family Life in Spain. In Guillen AM and Leon M. (eds) The Spanish Welfare State in European Context. Farnham: Ashgate, pp. 187-208.

Stone J, Berrington A and Falkingham J (2011) The changing determinants of UK young adults' living arrangements. Demographic Research, 25: 629-666.

Streeck W (2009) Re-Forming Capitalism: Institutional Change in the German Political Economy. Oxford: Oxford University Press.

Streeck W and Thelen C (2005) Beyond Continuity. Institutional Change in Advanced Political Economies. Oxford: Oxford University Press.

Taylor-Gooby P (2004) New Risks, New Welfare. Oxford: Oxford University Press. 
Taylor-Gooby P (2012) Root and Branch Restructuring to Achieve Major Cuts: The Social Policy Programme of the 2010 UK Coalition Government. Social Policy and Administration, 46 (1): 61-82.

Tikkanen J, Biggart A and Pohl A (2017) The diversity of education and welfare systems in Europe. In Walther A, Parreira do Amaral M, Cuconato M, Dale R (eds) Governance of Educational Trajectories in Europe. London: Bloomsbury, pp. 35-52.

Tosun J, Treib O and De Francesco F (2019) The impact of the European Youth Guarantee on active labour market policies: A convergence analysis. International Journal of Social Welfare, 28(4): 358-368.

Verd JM, Barranco O and Bolíbar M (2019) Youth unemployment and employment trajectories in Spain during the Great Recession: what are the determinants?. Journal for Labour Market Research, 53:4. DOI: 10.1186/s12651-019-0254-3

Verick S (2011) The Impact of the Global Financial Crisis on Labour Markets in OECD Countries: Why Youth and Other Vulnerable Groups Have Been Hit Hard. In: Islam I and Verick S (eds) From the Great Recession to Labour Market Recovery. London: Palgrave Macmillan, pp.119-145.

Walther A (2006) Regimes of youth transitions: Choice, flexibility and security in young people's experiences across different European contexts. Young, 14 (2): 119-139.

Walther A (2017) Support across life course regimes. A comparative model of social work as construction of social problems, needs, and rights. Journal of Social Work, 17(3): 277-301.

For correspondence: Martí López-Andreu, Alliance Manchester Business School, University of Manchester, Booth Street W, M156PB, Manchester, UK. E-mail: marti.lopezandreu@manchester.ac.uk

For correspondence: Joan Miquel Verd, Centre d'Estudis Sociologics Sobre la Vida Quotidiana i el Treball (Sociological Research Centre on Everyday Life and Work-QUIT), Institut d'Estudis del Treball (Institute for Labour Studies-IET), Universitat Autonoma de Barcelona, Building B. Campus of the Universitat Autonoma of Barcelona, 08193 Cerdanyola del Vallés, Barcelona, Spain. E-mail: joanmiquel.verd@uab.cat 